Jurnal Pemikiran Sosiologi Vol. 3 No. 1, Januari 2016

\title{
Review Buku: Understanding Digital Humanities
}

\author{
Oleh: \\ Arie Setyaningrum Pamungkas
}

\begin{abstract}
Abstrak
Artikel ini adalah sebuah review yang merupakan pembacaan secara kritis buku panduan (handbook) berjudul Understanding Digital Humanities mengenai kajian humaniora digital yang diedit oleh David M Berry pada tahun 2012. Dalam review ini selain dibahas resensi isi buku dan muatan tematik yang digagasnya, juga menyajikan perdebatan kritis mengenai penggunaan konsep Digital Humanities sebagai paradigma baru kajian sosial humaniora. Perdebatan ini meliputi gagasan Digital Humanities sebagai suatu konsep metodologis maupun sebagai praxis yang berkembang di masyarakat seiring perkembangan teknologi. Dengan menggunakan pendekatan analisis isi dan analisis wacana, tujuan dari review buku ini adalah memberikan pemaparan gagasan mengenai 'kajian humaniora digital' dan sekaligus pemahaman secara kritis atas implikasi sosiologis yang diakibatkannya.
\end{abstract}

\begin{abstract}
This article represents a 'review' which reflects a critical reading on the handbook of digital humanities entitled 'Understanding Digital Humanities' edited by David $M$ Berry in 2012. This review includes an essential summary and sub themes of the book and critical debates about the use of the concept of 'Digital Humanities' as a paradigm in social humanities, both as a methodological concept and praxis in our society as a result of technological development. Using content analysis and discourse analysis, the purposes of this book review are to provide an exploration of the notion of 'digital humanities studies'; and to envoke a critical understanding of its sociological implications.
\end{abstract}

Keywords: methodology, social humanities, digital humanities 


\section{A. Pendahuluan}

Buku Understanding Digital Humanities atau 'Memahami Kajian Humaniora Digital' ini merupakan semacam handbook atau buku pegangan yang berisi kumpulan beberapa artikel sebagai upaya terobosan untuk mengkaitkan kajian sosial humaniora dengan perkembangan teknologi digital. Secara spesifik, kajian Digital Humanities (biasa disingkat menjadi DH) menjadi area pengkajian penelitian dan pengajaran di bidang komputasi digital yang berpengaruh pada ruang lingkup kehidupan manusia. Kajian ini mencangkup upaya untuk mengeksplorasi materimateri yang telah direkam secara digital (digitized materials) dan materi-materi baru yang terdigitalisasikan (born digital materials).

Oleh karena itulah, kajian DH melingkupi penelitian yang dilengkapi oleh perangkat komputasi seperti Data Mining, Text Mining Tools, Text Analysis, Visual Analysis, Statistics, dan Digital Mapping) yang keseluruhannya dibahas melalui pendekatan Ilmu Sosial Humaniora. Dalam bab pengantar di buku ini, David M Berry sebagai editor menjelaskan perbedaan antara 'Kajian Humaniora Klasik' dengan 'Kajian Digital Humanities'. Menurutnya, kajian humaniora klasik membahas beragam praktek sosial dan budaya manusia sebagai suatu sistem pengetahuan yang berdasarkan konteks kesejarahan dimana manusia mulai mengembangkan teknologi awal dalam mengarsipkan pengetahuan dan melembagakannya baik secara sosial, ekonomi maupun politik. Ia menegaskan bahwa keseluruhan proses dalam kajian humaniora secara klasik yang dilembagakan itu hampir seluruhnya berlangsung melalui sejarah yang bersifat singular atau berjalan satu arah (David. M Berry, 2012: 20-22). Sementara kajian DH meskipun masih memuat karakteristik lama dari kajian humaniora klasik akan tetapi dalam pelembagaannya secara sosial yang berkarakter 'melipatgandakan' (multiplicity) memiliki dampak kultural, ekonomi dan politik yang berbeda dikarenakan pelembagaan itu berlangsung secara plural. Kemunculan internet dan jejaring dunia maya membuat praktek pelembagaan arsip dan dokumen sebagai materi kajian humaniora (baik secara tekstual maupun visual, bahkan materi secara audio visual) kemudian menjadi lebih kompleks dikarenakan individu maupun kelompok dan lembaga yang menaunginya terlibat secara partisipatorik di dalam merespon dan memanfaatkan fungsi keberadaan arsip dan dokumendokumen tersebut (ibid: 25-27). Praktek mendigitalkan dokumen sudah dimulai khususnya ketika teknologi komputasi berkembang di abad ke 20 sehingga memungkin untuk melipatgandakan persebaran informasi dan khususnya ilmu pengetahuan. Hal inilah yang kemudian mengundang perdebatan secara akademik khususnya berkenaan dengan metodologi yang dapat mengakomodasi kepentingan untuk mengkaji dampak atas pelipatgandaan informasi dan struktur kekuasaan yang berpengaruh dalam pelembagaan DH sebagai suatu disiplin ilmu baru yang bersifat interdisipliner atau bahkan multi disipliner. 


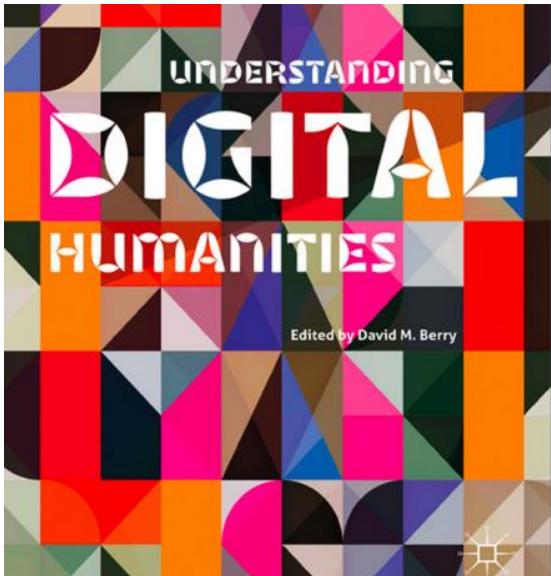

Gambar: Sampul Buku Understanding Digital Humanities.

Editor: David M. Berry. Penerbit: Pallgrave Macmillan, NY. Tahun: 2012.ISBN: 978-0-230-29264-2 (harback) / 978-0-230-29565-9 (paperback). Tebal: 337 halaman.

\section{B. Metode Review: Struktur dan Tema Buku}

Artikel ini saya susun pertama-tama berdasarkan pengakajian analisis isi atas buku utama yakni Understanding Digital Humanities dengan menelusuri konsep dan tema-tema yang dibahas oleh buku ini. Kemudian saya merujuk dengan membandingkan buku ini dengan buku-buku yang lain dengan menggunakan analisis wacana, baik buku yang bertema serupa maupun buku-buku yang memperdebatkan tema kajian humaniora digital. Melalui metode analisis isi, didapatkan struktur isi dan tema buku, sedangkan melalui metode analisis wacana dapat membandingkan perdebatan konsep mengenai kajian humaniora digital ini secara kritis dan implikasinya secara sosiologis di masyarakat luas.

Struktur buku ini secara umum dijabarkan melalui dua struktur utama yakni; (1) Pembahasan secara konseptual, definisi operasional dan wilayah kajian yang dapat dibahas melalui pendekatan Digital Humanities; dan (2) metode dan praktek Digital Humanities serta implikasinya pada perkembangan masyarakat moderen khususnya di era masyarakat jejaring (network society). Pembahasan secara konseptual sebagaimana yang telah diungkapkan di muka berkenaan dengan bagaimana informasi, materi-materi sejarah, arsip dan dokumen yang terdokumentasikan secara digital mempengaruhi pelembagaan ilmu pengetahuan yang dimediasikan oleh teknologi baru seperti teknologi komputasi dan internet. Medium baru inilah yang mempengaruhi bagaimana definisi atas 'materi pengetahuan yang terdokumentasikan secara digital dioperasikan melalui beragam praktek sosial. Hal yang paling mengemuka di dalam pembahasan buku ini berkenaan dengan definisi operasional konsep Digital Humanities, yaitu bagaimana menandai wilayah-wilayah kajian (area studies) yang dapat mempertemukan beragam disiplin ilmu, dan beragam metode untuk menganalisa kasus-kasus yang dapat diteliti sebagai topik kajian. Beberapa artikel berkenaan dengan struktur pertama isi buku ini mengenai konsep, definisi operasional dan wilayah kajian dapat kita cermati pada bab-bab awal di dalam buku ini, seperti contohnya sebagai berikut yang saya klasifikasikan ke dalam tabel analisis isi. 
Tabel.1. Content Analysis 1: Artikelartikel di dalam buku yang membahas tema mengenai konsep, definisi operasional dan wilayah kajian yang dapat menggunakan pendekatan Digital Humanities.

\begin{tabular}{|c|c|c|}
\hline $\begin{array}{l}\text { Judul Artikel } \\
\text { (Urutan sub bab) }\end{array}$ & Penulis & $\begin{array}{ll}\text { Kata } & \text { Kunci } \\
\text { Utama } & \\
\end{array}$ \\
\hline $\begin{array}{l}\text { Introduction: } \\
\text { Understanding } \\
\text { Digital Humanities } \\
\text { (1) }\end{array}$ & $\begin{array}{l}\text { David M } \\
\text { Berry }\end{array}$ & $\begin{array}{l}\text { Digital } \\
\text { Humanities, } \\
\text { Archives, } \\
\text { Digitized } \\
\text { Materials, } \\
\text { Literature, } \\
\text { History } \\
\end{array}$ \\
\hline $\begin{array}{lr}\text { An } & \text { Interpretation } \\
\text { Of } & \text { Digital } \\
\text { Humanities (2) }\end{array}$ & $\begin{array}{l}\text { Leighto } \\
n \text { Evans } \\
\text { dan } \\
\text { Stan } \\
\text { Rees }\end{array}$ & $\begin{array}{l}\text { Digital } \\
\text { Humanities, } \\
\text { Computing } \\
\text { Mediated } \\
\text { Materials, } \\
\text { Information }\end{array}$ \\
\hline $\begin{array}{l}\text { Archives in Media } \\
\text { Theory: Material } \\
\text { Media Archeology } \\
\text { and Digital } \\
\text { Humanities (5) }\end{array}$ & $\begin{array}{l}\text { Jussi } \\
\text { Parrika }\end{array}$ & $\begin{array}{l}\text { Digital } \\
\text { Humanities, } \\
\text { Media Theory, } \\
\text { Digitized } \\
\text { Materials, } \\
\text { Archives }\end{array}$ \\
\hline $\begin{array}{l}\text { The Aesthetic of } \\
\text { Hidden Things (7) }\end{array}$ & $\begin{array}{l}\text { Scott } \\
\text { Dexter }\end{array}$ & $\begin{array}{l}\text { Archives, } \\
\text { Historical } \\
\text { materials, Digital } \\
\text { Humanities }\end{array}$ \\
\hline $\begin{array}{l}\text { The Meaning and } \\
\text { the Mining of Legal } \\
\text { Texts (8) }\end{array}$ & $\begin{array}{l}\text { Milleire } \\
\text { Hilldebra } \\
n t\end{array}$ & $\begin{array}{l}\text { Digital } \\
\text { Humanities, Text } \\
\text { Mining, Legal } \\
\text { Issues }\end{array}$ \\
\hline $\begin{array}{l}\text { Have the } \\
\text { Humanities always } \\
\text { been Digital? For } \\
\text { an Understanding } \\
\text { of Digital } \\
\text { Humanities in the } \\
\text { Context of Original } \\
\text { Technicity (9) }\end{array}$ & $\begin{array}{l}\text { Frederic } \\
a \\
\text { Frabetti }\end{array}$ & $\begin{array}{l}\text { Digital } \\
\text { Humanities, } \\
\text { Authenticity, } \\
\text { Social and } \\
\text { Humanities }\end{array}$ \\
\hline $\begin{array}{l}\text { Cultures of } \\
\text { Formalization: } \\
\text { Towards an } \\
\text { Encounter between } \\
\text { Humanities and } \\
\text { Computing (15) }\end{array}$ & $\begin{array}{l}\text { Joris } \\
\text { Van } \\
\text { Zundert } \\
\text { et.al }\end{array}$ & $\begin{array}{l}\text { Digital } \\
\text { Humanities, } \\
\text { Computatation, } \\
\text { Formalization of } \\
\text { Culture }\end{array}$ \\
\hline $\begin{array}{l}\text { Transdisiplinary of } \\
\text { Digital } \\
\text { Humanities: Lesson } \\
\text { Learntr from } \\
\text { Developing Text } \\
\text { Mining Tools for } \\
\text { Textual Analysis } \\
\text { (16) }\end{array}$ & $\begin{array}{l}\mathrm{Yu} \text { Wei } \\
\text { Lin }\end{array}$ & $\begin{array}{l}\text { Digital } \\
\text { Humanities, Text } \\
\text { Mining, } \\
\text { Interdiciplines, } \\
\text { Multi diciplines, } \\
\text { Transdiciplinary } \\
\text { Approach }\end{array}$ \\
\hline
\end{tabular}

Berdasarkan tabel pertama (1) mengenai analisis isi dari artikelartikel yang dibahas di dalam buku, nampak bahwa definisi mengenai Digital Humanities merupakan tema utama eksplorasi para penulis. Secara umum eksplorasi tersebut berkenaan dengan obyek kajian, serta disiplin ilmu apa saja yang dapat mengembangkan tema utama ini. Area of inquiry atau wilayah kajian dimana obyek penelitian yang terutama berkenaan dengan aspek materi atau informasi yang direkam secara digital, baik arsip sejarah masa lampau atau bahkan yang bersifat real time kemudian menjadi basis bagi eksplorasi kajian digital humanities. Dalam konteks ini, sejarah dimaterikan dan memiliki rekam jejak yang lebih spesifik dalam perkembangan peradaban manusia. Secara khusus, para penulis berbagi kemiripan dalam menurunkan konsep mengenai 'apa yang dimaksut dengan kajian humaniora digital ini', yaitu penggunaan metode komputasi baik secara kuantitatif maupun secara kualitatif dalam menganalisis datadata digital dalam jumlah yang sangat besar. Wacana mengenai 'Digital Humanities' oleh karenanya tidak dapat dilepaskan dengan konteks keberadaan Big Data yang perkembangannya semakin tumbuh pesat. Meski demikian, ada penulis yang menekankan pula pentingnya aspek etis dan legal dalam memberlakukan materi-materi digital tersebut. Hal ini terutama berkenaan dengan sumber-sumber perolehan materi (otentisitas), serta siapa-siapa saja yang dapat memperoleh akses informasi pada materi digital itu dan ditujukan untuk kepentingan apa saja. 
Tabel. 2. Content Analysis 2: Artikelartikel di dalam buku yang membahas mengenai Metode, Praktek dan Implikasi Kajian Digital Humanities

\begin{tabular}{|c|c|c|}
\hline $\begin{array}{l}\text { Judul Artikel } \\
\text { (Urutan sub } \\
\text { bab) }\end{array}$ & Penulis & $\begin{array}{ll}\text { Kata } & \text { Kunci } \\
\text { Utama } & \end{array}$ \\
\hline $\begin{array}{l}\text { How We Think? } \\
\text { Transforming } \\
\text { Power and } \\
\text { Digital } \\
\text { Technologies } \\
\text { (3) }\end{array}$ & $\begin{array}{l}\text { N Katherine } \\
\text { Hayles }\end{array}$ & $\begin{array}{l}\text { Power } \\
\text { Relations, } \\
\text { Digital } \\
\text { Technologies, } \\
\text { Scale and } \\
\text { Measurement } \\
\end{array}$ \\
\hline $\begin{array}{l}\text { Digital Methods: } \\
\text { Five Challenges } \\
\text { (4) }\end{array}$ & $\begin{array}{l}\text { Bernhard } \\
\text { Rieder dan } \\
\text { Theo } \\
\text { Roehle } \\
\end{array}$ & $\begin{array}{l}\text { Digital } \\
\text { Methods, } \\
\text { Objectivity, } \\
\text { Universalism } \\
\end{array}$ \\
\hline $\begin{array}{l}\text { Cannocalism } \\
\text { and the } \\
\text { Computational } \\
\text { Turn (6) }\end{array}$ & $\begin{array}{l}\text { Carroline } \\
\text { Basset }\end{array}$ & $\begin{array}{l}\text { Simulation, } \\
\text { Game Studies, } \\
\text { Software } \\
\text { Studies, } \\
\text { Canonization } \\
\end{array}$ \\
\hline $\begin{array}{l}\text { Present, } \quad \text { Not } \\
\text { Voting: Digital } \\
\text { Humanities in } \\
\text { Panopticon (10) }\end{array}$ & $\begin{array}{l}\text { Melissa } \\
\text { Terras }\end{array}$ & $\begin{array}{l}\text { Digital Identity, } \\
\text { Data Legacy }\end{array}$ \\
\hline $\begin{array}{l}\text { Analysis Tools } \\
\text { for Research } \\
\text { Methodology: Is } \\
\text { there an } \\
\text { Epistemology of } \\
\text { Patterns? (11) }\end{array}$ & Dan Dixon & $\begin{array}{l}\text { Epistemic } \\
\text { Orientation, } \\
\text { Abduction, } \\
\text { Aphophenia, } \\
\text { Interventionist } \\
\text { Approach }\end{array}$ \\
\hline $\begin{array}{l}\text { Do Computer } \\
\text { Dreams of } \\
\text { Cinema? } \\
\text { Computer } \\
\text { Analysis and } \\
\text { Visualization } \\
(12)\end{array}$ & $\begin{array}{l}\text { Adelheid } \\
\text { Hefberger }\end{array}$ & $\begin{array}{l}\text { Automated } \\
\text { Analysis, Visual } \\
\text { and Virtual } \\
\text { Analysis }\end{array}$ \\
\hline $\begin{array}{l}\text { The Feminist } \\
\text { Critique: } \\
\text { Mapping } \\
\text { Controversy in } \\
\text { Wikipedia (13) }\end{array}$ & $\begin{array}{l}\text { Morgan } \\
\text { Currie }\end{array}$ & $\begin{array}{l}\text { Feminism, } \\
\text { Wikipedia, } \\
\text { Digital Mapping }\end{array}$ \\
\hline $\begin{array}{l}\text { How to } \\
\text { Compare One } \\
\text { Million Images? } \\
(14)\end{array}$ & $\begin{array}{l}\text { Lev } \\
\text { Manovich }\end{array}$ & $\begin{array}{lr}\text { Visual and } \\
\text { Virtual Analysis }\end{array}$ \\
\hline
\end{tabular}

Berdasarkan tabel kedua (2) mengenai analisis isi atas artikelartikel di dalam buku yang membahas metode, praktek dan implikasi kajian Digital Humanities, nampak bahwa definisi operasional mengenai Digital Humanities justru jarang muncul di dalam teks-teks. Hal ini dikarenakan para penulis yang membahas metode dan praktek pemanfaatan teknologi digital dan pengaruhnya lebih memfokuskan diri pada metode penelitian yang mereka lakukan. Metode-metode inilah yang sebenarnya telah lama dimunculkan seiring dengan kemunculan teknologi digital dan internet sejak setelah Perang Dunia Kedua dimana pada awalnya teknologi digital, komputasi dan teknologi informasi ditujukan bagi kepentingan intelejen dan bahkan tujuan militer hingga akhirnya menjadi medium baru komunikasi yang berlangsung secara global.

Meski demikian, perkembangan dunia digital dan bagaimana materi-materi yang direkam secara digital termasuk yang berlangsung secara real time telah mengubah landskap sosial, ekonomi, politik bahkan budaya di dunia. Ini misalnya nampak pada metode digital mapping dimana cara-cara merekam ilmu pengetahuan untuk dibagikan kepada banyak orang secara online difasilitasi oleh Wikipedia misalnya. Metode yang kemudian berkembang dalam kajian Digital Humanities pun menjadi beragam, seperti misalnya metode Text Mining Analysis yang berkembang dari analisis atas Hypertexts dan Hypermedia, perkembangan di dalam teknikteknik statistik, hingga ke metode etnografi visual, etnografi virtual, metode penelitian hermeneutika internet dan metode lain yang berbasis pada analisis kualitatif. Dalam konteks keragaman atas metode-metode penelitian yang dapat dipraktekkan dalam kajian Digital Humanities inilah yang menurut para penulis akan terus berkembang di masa depan mengingat perubahan sosial yang demikian pesat dipengaruhi oleh 
medium teknologi digital dan internet dikarenakan semakin meningkatnya populasi penduduk dunia yang berinteraksi dan berpartisipasi dalam masyarakat jejaring di dunia maya. Dengan pengertian lain, dampak utama adalah menciptakan pelembagaan ruang baru bagi ilmu pengetahuan, yakni ruang yang lebih bersifat partisipatorik.

\section{Ruang yang bersifat} partisipatorik ini di satu sisi menunjukkan bahwa keswadayaan (volunterisme) di dalam masyarakat global adalah sesuatu yang melintasi batasan kelas dan identitas sosial, sesuatu yang menunjukkan harapan optimis tentang pentingnya "berbagi" melalui fasilitas medium internet. Akan tetapi disisi lain, sifat keswadayaan itu bukan berarti tidak problematis. Hal ini dikarenakan pada prakteknya, akses pada materimateri rekam digital maupun informasi acapkali secara geopolitik menjadi kecenderungan dominasi atas pengetahuan tertentu. Kontestasi atas pengetahuan kemudian menjadi semacam "pertarungan yang bersifat terbuka" dimana dalam kenyataannya hegemoni atas penguasaan informasi tertentu tetap saja hanya milik sekelompok orang tertentu sedangkan sebagian besar "populasi dunia" yang mengakses internet dan data-data digital tersebut cenderung berposisi sebagai konsumen belaka.

\section{Diskusi: Kritik dan Perdebatan Mengenai Konsep Digital Humanities}

Buku Understanding Digital Humanities ini diterbitkan pertama kali pada tahun 2012, dan bukanlah buku yang pertama kalinya diterbitkan sebagai inisiasi ekplorasi akademik mengenai kajian Digital Humanities. Salah satu buku yang juga menawarkan tema serupa berjudul A Companion to Digital Humanities yang diterbitkan oleh Blackwell Publishing, justru lebih awal yaitu pada tahun 2008, dengan editor-editor Susan Schreibmann, Ray Siemens, dan John Unstworth. Buku A Companion to Digital Humanities ini agak sedikit berbeda dengan buku Understanding Digital Humanities. Yaitu secara spesifik tidak memperbincangkan definisi konseptual mengenai Digital Humanities melainkan lebih menekankan pada praktek pemanfaatan materi - materi digital dan informasi lainnya yang direkam secara digital melalui integrasi multimedia, pemanfaatan metadata, dan perubahan lingkungan yang bersifat dinamis (dynamic environments). Dengan kata lain, buku ini lebih banyak memberikan petunjuk mengenai bagaimana mengolah data-data, arsip, informasi secara digital, serta medium apa saja yang dapat dimanfaatkan dan mengkalkulasi keuntungan atau manfaat atas praktek merekam pengetahuan secara digital dan bagaimana membagikannya dengan pelembagaan sosial.

$\begin{array}{lrr}\text { Sementara itu, } & \text { meskipun } \\ \text { buku Understanding } & \text { Digital } \\ \text { Humanities membuka } & \text { diskusi }\end{array}$
mengenai konsep atas kajian digital humaniora, sayangnya penyusunan buku ini kurang sistematis. Buku ini hanya mengurutkan tema-tema berdasarkan isu-isu mana yang paling populer dan berkembang mengenai praktek merekam data dan informasi secara digital. Buku ini tidak dibagi berdasarkan 'kategorisasi tematik', sehingga ketika kita membaca buku ini tanpa 
dikerangkai dalam 'payung tematik' maka pembacanya akan mengalami kesulitan untuk mengikuti satu artikel dengan artikel yang lainnya yang berbeda-beda topik pembahasannya. Oleh karena itu, pembaca buku ini harus memahami logika buku ini dengan dilandasi oleh pengetahuan dasar mengenai sejarah perkembangan teknologi moderen khususnya semenjak ditemukannya teknologi radio, televisi, komputer , satelit, dan teknologi 'image scanning' - atau pemindaian citra. Tanpa dasar pengetahuan itu, membaca buku ini seperti langsung 'terjerembab' ke dalam analisis-analisis yang bersifat kasuistik saja. Padahal tujuan dari buku ini adalah mempopulerkan gagasan mengenai Digital Humanities yang bersifat 'holistik'. Yaitu mengenai 'spektrum perubahan dunia yang semakin terpolarisasikan sekaligus yang semakin terpusat' atau landskap transformasi sosial dan pengetahuan yang berlangsung secara 'sentripetal dan sentrifugal' dikarenakan perkembangan teknologi komunikasi dan informasi.

Dalam pengamatan saya, secara khusus kritik yang tajam dan perdebatan atas konsep 'Digital Humanities' diajukan oleh setidaknya dalam dua buku lainnya yang lebih terbaru, yakni yang keduanya diterbitkan pada tahun 2014. Yang pertama dirintis oleh sekelompok intelektual dan sarjana yang bergabung di dalam komunitas 'Debates in the Digital Humaties' yang berbasis di City University New York. Mereka menerbitkan buku berjudul serupa yang dieditori oleh Matthew K Gold, seorang profesor di bidang kajian budaya dan media dan diterbitkan pada tahun 2014.
Berbeda dengan dua buku sebelumnya mengenai Digital Humanities, buku yang merangkum perdebatan mengenai 'paradigma' konsep digital humanities ini menekankan pada pentingnya meletakkan 'platform' secara kritis, baik secara akademik, dan terutama secara politik di dalam mengkerangkai kepentingan untuk mempopulerisasikan definisi dan melembagakan praktek mengenai 'digital humanities'. Dalam sejarahnya, konsep mengenai Digital Humanities digunakan pertama kalinya oleh Roberto Busa pada tahun 1940 yang menggunakan teknologi komputasi untuk melacak kode-kode dan meretas kode (decoding) untuk analisis linguistik dan menyusunnya sebagai indeks rekaman data kepustakaan. Sementara itu, praktek merekam data secara digital mulai berlangsung secara masif pada era tahun 1980an semenjak ditemukannya teknologi untuk digital image processing yang dapat diintegrasikan ke dalam sistem komputasi dan bahkan melalui teknologi satelit kemudian ikut mendorong munculnya teknologi internet. Dengan melihat pada konteks kesejarahan modernitas dan bagaimana pengetahuan direkam dan dimediasikan oleh teknologi digital, karenanya pembahasan mengenai konsep 'Digital Humanities' tidak bisa semata-mata dapat kita terima sebagai suatu perkembangan mode of production era kapitalisme tingkat lanjut (late capitalism) secara taken for granted (langsung diterima begitu saja). Hal ini dikarenakan praktek dan pemanfaatan data digital bukan hanya mensubsidi persebarluasan informasi dan pelembangaan pengetahuan baru saja, melainkan 
juga menjadi sarana bagi kepentingan kapitalistik yang secara hegemonik terus mengkolonisasi 'ruang-ruang perebutan baru atas sumber daya informasi dan akses pada teknologi informasi' itu sendiri.

Hal hampir senada dinyatakan oleh Christian Fuchs dan Marisol Sandoval dalam buku mereka berjudul Social Media and Information Society yang diterbitkan oleh Routledge pada tahun 2014. Fuchs dan Sandoval menekankan bahwa di dalam aspek digitalisasi pengetahuan melalui jejaring dunia maya memiliki implikasi sosiologis secara signifikan. Yaitu sesungguhnya menyembunyikan sebuah struktur penindasan kemanusiaan yang lain di dalam hierarki 'human labor' industri media dan teknologi informasi termasuk yang difasilitasi oleh internet. Kepentingan untuk merekam data-data, arsip dan pengetahuan secara digital menjadi proyek yang mengutamakan 'manfaat sosial' tetapi lebih diarahkan pada tujuan melembagakan pengetahuan yang secara hegemonik dikuasai oleh agensi pemilik modal besar dan kapitalis dunia. Di sisi lain, arus perekaman data yang memiliki kecendrungan berlangsung secara instan, dan bersifat real-time khususnya melalui media sosial justru didominasi oleh kepentingan agensi korporasi raksasa penyelenggara media sosial dan yang memanfaatkannya untuk mendorong penyeragaman pola-pola konsumsi di seluruh dunia. Melalui analisis kritis dan marxisme struktural, Fuchs dan Sandoval menegaskan bahwa agensi pelembagaan pengetahuan yang dibangun melalui korporasi melalui teknologi informasi semakin memperlebar jurang kesenjangan (gap) dalam struktur sosial melalui praktek kapitalisme neoliberal yang bersifat antagonistik, yakni:

(1) Antagonisme hubungan antar kelas-kelas sosial yang bersifat antogonistik;

(2) Antagonisme hubungan antar nilai kegunaan dan nilai pertukaran;

(3) Antagonisme hubungan sumberdaya produktif (productive forces) dan relasi produksi;

(4) Antagonisme hubungan antara produksi yang ditujukan bagi pemanfaatan sosial (socialized production) dengan produksi kapitalis yang ditujukan bagi kepentingan bersifat privat (capitalistic, private appropriation); dan

(5) Antagonisme antara nilai fiktif suatu keuangan kapital dengan keuntungan aktual yang diperoleh kapital itu sendiri ketika diperdagangkan (atau dapat digambarkan sebagai antagonisme nilai atau manfaat virtual dengan nilai riil atas suatu kapital)

Kelima hubungan yang bersifat antagonis inilah yang menjadi implikasi sosiologis melalui praktek Digital Humanities. Para penyelenggara jasa yang mengelola Big Data, misalnya menggunakan 'informasi' sebagai komoditas baru untuk menentukan kecenderungan pasar. Oleh karenanya, Fuchs dan Sandoval menyarankan agar pendefinisian mengenai Digital Humanities juga seharusnya meliputi aspek-aspek kritis perkembangan kapitalisme yang memanfaatkan medium teknologi informasi dan komunikasi yang mereproduksi 
kesenjangan antar kelas sosial. Hal ini dikarenakan informasi adalah sumber pengetahuan, dan oleh karenanya dapat berfungsi sebagai 'komoditas', sehingga menjadi sangat rentan untuk direduksi bagi kepentingan 'profit making' semata.

\section{Penutup}

Tidak dapat dipungkiri bahwa perkembangan teknologi digital merupakan bagian yang tidak terpisahkan dalam kehidupan kita sehari-hari. Upaya untuk merekam pengetahuan baik sebagai arsip sejarah peradaban manusia maupun sebagai sumber pengetahuan baru bagi publik kini semakin memperoleh tuntutan untuk direalisasikan sebagai sebuah agenda transformasi sosial. Upaya inilah yang kemudian mendorong eksplorasi baru bagi perkembangan ilmu pengetahuan itu sendiri tak terkecuali kajian sosial humaniora. Perkembangan ini bagaimanapun, sebagaimana yang digagas oleh buku ini Understanding Digital Humanities merupakan sesuatu yang tidak dapat kita hindari akan menjadi medium yang bermanfaat bagi perluasan partisipasi sosial di dalam ikut serta 'membangun dan membentuk' relasi kuasa pengetahuan. Dengan kata lain, upaya-upaya untuk mengenali praktek dan pemanfaatan medium teknologi semakin tidak dapat kita abaikan begitu saja.

Meski demikian, di sisi lain kajian ilmu sosial humaniora perlu mengembangkan perspektif yang bersifat kritis di dalam mencermati konsep dan praktek mengenai Digital Humanities ini. Implikasi pelembagaan pengetahuan melalui medium digital yang disebarluaskan melalui jejaring dunia maya secara sosiologis juga perlu dicermati sebagai upaya perjuangan baru untuk mengikutsertakan kelas-kelas sosial yang termarginalisasikan sehingga mereka memiliki keberdayaan dan bersikap kritis di dalam mengkonsumsi informasi dan di dalam mengakses ilmu pengetahuan. Buku ini mengakui bahwa perdebatan secara konseptual mengenai Digital Humanities belum-lah bersifat "tetap" (fixed), melainkan masih terbuka untuk dikontestasikan mengingat area of inquiry atau wilayah jelajah kajiannya yang demikian kompleks, beragam, dan melintas antar disiplin keilmuan. 
Jurnal Pemikiran Sosiologi Vol. 3 No. 1, Januari 2016

Arie Setyaningrum Pamungkas

Review Buku: Understanding Digital Humanities

\section{Daftar Pustaka}

Berry, M. David (ed). (2012). Understanding Digital Humanities. NY: Pallgrave Macmillan

Fuchs, Chritian dan Sandoval, Marisol. (2014). Social Media and Information Society. London: Routledge

Gold, Matthew (ed). (2014). Debates in the Digital Humanities. Minnesota: University of Minnesota Press

McCarthy, Willard. (2005). Humanities Computing. Bassingstokes: Pallgrave Macmillan

Schreiben, Susan, Siemens, Ray, dan Unsworth, John. (2008). A Companion to Digital Humanies. NY: Blackwell Publishing

\section{Sumber Internet}

Thaller, Manfred. (2012). "Controversies Around the Digital Humanities". Historical Social Research. 37 (3). Diakses melalui website http://gesis.org./en/aktuelleausgaben/aktuelle-hefte-20102012-digitalhumanities/. Diakses pada tanggal 10 Desember 2015. 